\title{
A new hyperapolytic species, Trilocularia eberti sp. $n$. (Cestoda: Tetraphyllidea), from Squalus cf. mitsukurii (Squaliformes: Squalidae) off South Africa with comments on its development and fecundity
}

\author{
Maria Pickering and Janine N. Caira
}

Department of Ecology and Evolutionary Biology, 75 N. Eagleville Rd., Unit 3043, University of Connecticut, Storrs, Connecticut 06269-3043, USA

\begin{abstract}
A new species of tetraphyllidean cestode in the genus Trilocularia is described from an undescribed shark species, Squalus cf. mitsukurii, off the coast of South Africa. Trilocularia eberti sp. n. is the second known member of its genus, and like its congener, T. gracilis (Olsson, 1866-1867) Olsson, 1869, is extremely hyperapolytic, dropping proglottids from its strobila while they are still very immature. Characteristic of the genus, it possesses a distinctive scolex with triloculated bothridia, but differs conspicuously from its congener in its possession of an anterior loculus that is much larger in width relative to the paired posterior loculi, and also in its possession of an anterior, enlarged region of its free proglottids that is triangular with a slit-like ventral aperture, rather than rounded and cup-like. This anterior region of the free proglottid is used in attachment, and its development is described. For assessment of fecundity, an attempt was made to record all free proglottids of all ages found in both host individuals, and yielded an average estimate of 362 free proglottids being produced per individual worm of T. eberti sp. n. Both Trilocularia species parasitize sharks of the genus Squalus, and given the host specificity typically exhibited by tetraphyllideans and preliminary examinations of other members of this shark genus, it is likely that other Squalus species will be found to host additional new Trilocularia species.
\end{abstract}

Keywords: tapeworms, taxonomy, growth, life history, sharks, parasites

The taxon ultimately referred to as Trilocularia Olsson, 1869 was first mentioned in the literature by Olsson (1866-1867, p. 42) who reported it from the spiral intestine of the spiny dogfish, Squalus acanthias L., off the coast of Sweden, under the heading "Phyllobothrideum acanthiae-vulgaris n. sp. inquir". In 1869 Olsson formally erected the genus Trilocularia, establishing this species as the type, but under the name Trilocularia gracilis Olsson, 1869. Although this species has had a convoluted nomenclatural past (see Euzet 1952), and has received much attention (e.g., McCullough and Fairweather 1983, 1984, McCullough et al. 1986, Henderson et al. 2002), the genus has remained monotypic since its erection. In addition to its possession of distinctive triloculated bothridia, this species is unusual in being one of three known extremely hyperapolytic tetraphyllidean cestodes (see Fyler 2011), in that the terminal proglottids are released from the strobila prior to the development of reproductive organs, and subsequently complete their development as free proglottids in the spiral intestine of the host (see also Yorkeria saliputium Caira, Jensen, et Rajan, 2007 and Acanthobothrium margieae Fyler, 2011 - Caira et al. 2007, Fyler 2011).
The collection of tapeworms from a novel shark species, identified preliminarily as Squalus cf. mitsukurii, off South Africa has led to the discovery of a second species of Trilocularia. This is the second species of Trilocularia to be described parasitizing a member of the shark genus Squalus L., which, given that only a small subset of the 27 species of Squalus have been examined for cestodes, suggests that the cestode genus Trilocularia is likely more speciose than originally thought. This is the first record of a tetraphyllidean cestode from an elasmobranch found off South Africa.

\section{MATERIALS AND METHODS}

Sharks were collected off the coast of South Africa (between $36^{\circ} 41.1^{\prime} \mathrm{S}, 20^{\circ} 37.6^{\prime} \mathrm{E}$ and $34^{\circ} 25.3^{\prime} \mathrm{S}, 25^{\circ} 49.8^{\prime} \mathrm{E}$ ) on April 18,2010 as by-catch from a hake survey conducted by South African Coastal Marine Management on the FRV Africana using a bottom trawl at depths ranging from 262 to $447 \mathrm{~m}$. They were preliminarily identified as representing a new, as of yet undescribed, species that resembles Squalus mitsukurii Jordan et Snyder, 1903 by D. Ebert (pers. comm.); molecular data generated for these specimens by Naylor et al. (2012) confirmed this, and thus, following Naylor et al. (2012), these sharks are 


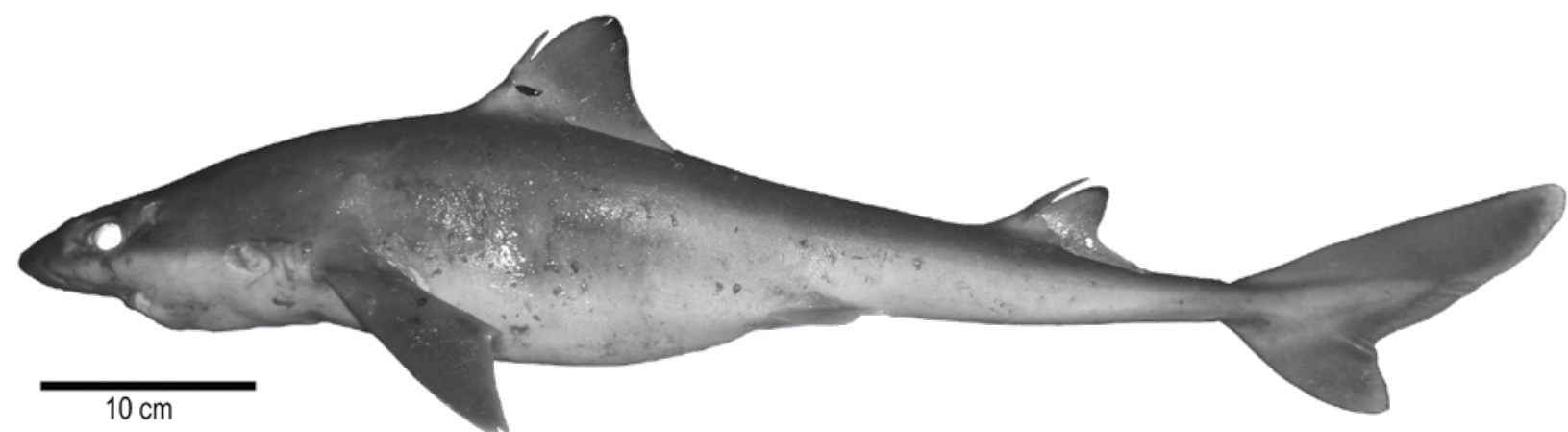

Fig. 1. Photograph of host shark species, Squalus cf. mitsukurii (AF-21).

referred to here as Squalus cf. mitsukurii. In total, six specimens of Squalus cf. mitsukurii (five females $69.5-100 \mathrm{~cm}$ in total length [TL] and one male $83 \mathrm{~cm} \mathrm{TL}$ ) were necropsied. Data and images of these specimens (Nos. AF-21, AF-22, AF-33, AF-100, AF-102, AF-113) can be accessed by searching the collection code and collection numbers in the Global Cestode Database at http://elasmobranchs.tapewormdb.uconn.edu. In addition, an image of one specimen (AF-21) is provided in Fig. 1. In each case the spiral intestine was removed, opened with a longitudinal incision, and examined for cestodes. Cestodes were recovered from two females (AF-21 and AF-22) 69.5 and $71.5 \mathrm{~cm}$ in TL. A subset of cestodes found in each host was placed in $95 \%$ ethanol for future molecular work and a subset was placed in $4 \%$ formalin buffered sea water for morphological examination. The spiral intestine of each shark was also fixed in $4 \%$ formalin buffered sea water; after about 1 week the formalin-fixed worms and spiral intestines were transferred to $70 \%$ ethanol.

For assessment of fecundity, an attempt was made to record all free proglottids of all ages found in both hosts; although not all were formally used in the description of the new cestode, many were prepared as whole mounts as described below to explore development of free proglottids.

Scoleces and free proglottids fixed for morphological analyses were prepared as whole mounts for light microscopy, for scanning electron microscopy (SEM), and as serial sections for histological work. Specimens were prepared for whole mounts as follows: they were hydrated in a graded ethanol series, stained in Delafield's hematoxylin, differentiated in tap water, destained in acidic $70 \%$ ethanol, placed in basic $70 \%$ ethanol, flattened under small pieces of glass slides, dehydrated in a graded ethanol series, cleared in methyl salicylate, and mounted in Canada balsam on glass slides. Measurements were taken using a SPOT Diagnostic Instrument digital camera system mounted on a Zeiss Axioskop 2 and SPOT software (version 4.5). Measurements are presented as the range, followed in parentheses by the mean, standard deviation, number of worms measured, and, when more than one measurement per worm was made, the total number of measurements taken. Measurements of mature, gravid, and dehisced free proglottids were combined given that the differences among proglottids of these stages were subtle. All measurements are in micrometres unless otherwise indicated. Microthrix terminology follows Chervy (2009). Six free proglottids and, initially, one scolex was prepared for SEM as follows: they were hydrated in a graded series of ethanol, placed in osmium tetroxide overnight, dehydrated in a graded series of etha- nol, placed in hexamethyldisilazane (HDMS) (Ted Pella, Inc., Redding, California), and allowed to air dry in a fume hood. The specimens were attached to aluminium stubs with double-sided carbon tape tabs (Ted Pella, Inc., Redding, California), sputter coated with 30-nm gold/palladium, and examined with a LEO/ Zeiss DSM982 Gemini field emission scanning electron microscope. One additional scolex was unmounted from a slide by immersion in methyl salicylate for one week and was prepared for SEM as described above. Six free proglottids were prepared for histological sectioning as follows. They were dehydrated in a graded ethanol series, cleared in xylene, embedded in paraffin, and sectioned at $8 \mu \mathrm{m}$ intervals using an Olympus CUT4060 retracting rotary microtome. Sections were then placed on glass slides flooded with $3 \%$ sodium silicate, dried on a slide warmer overnight, and then stained with Delafield's hematoxylin, differentiated in Scott's solution, counterstained with eosin, cleared in xylene and mounted in Canada balsam on glass slides.

No type specimens from Olsson's 1866-1867 description appear to be in existence, and thus, for comparative purposes, voucher specimens of Trilocularia gracilis collected by Olsson in 1868 (Göteborg Natural History Museum) from the type host, Squalus acanthias, and type locality (Bohuslan County, Sweden) were examined. However, those specimens did not include any free proglottids, therefore, additional specimens of $T$. gracilis were collected from $S$. acanthias from the northwestern Atlantic Ocean $\left(41^{\circ} 4^{\prime} \mathrm{N}, 71^{\circ} 34^{\prime} \mathrm{W}\right)$. Specimens were prepared for light microscopy and SEM as described above.

Museum abbreviations used are as follow: IPCAS, Institute of Parasitology, Biology Centre ASCR, České Budějovice, Czech Republic; LRP, Lawrence R. Penner Parasitology Collection, Department of Ecology and Evolutionary Biology, University of Connecticut, Storrs, Connecticut, USA; SAMCTA, South African Museum Cape Town Invertebrate Collection, Cape Town, South Africa; USNPC, U.S. National Parasite Collection, Beltsville, Maryland, USA.

\section{RESULTS}

Trilocularia eberti sp. n.

Figs. 2-23

Description. Based on whole mounts of six worms and 14 free proglottids: three mature, eight gravid, and three dehisced; two scoleces and six free proglottids observed with SEM; cross sections of six gravid proglot- 

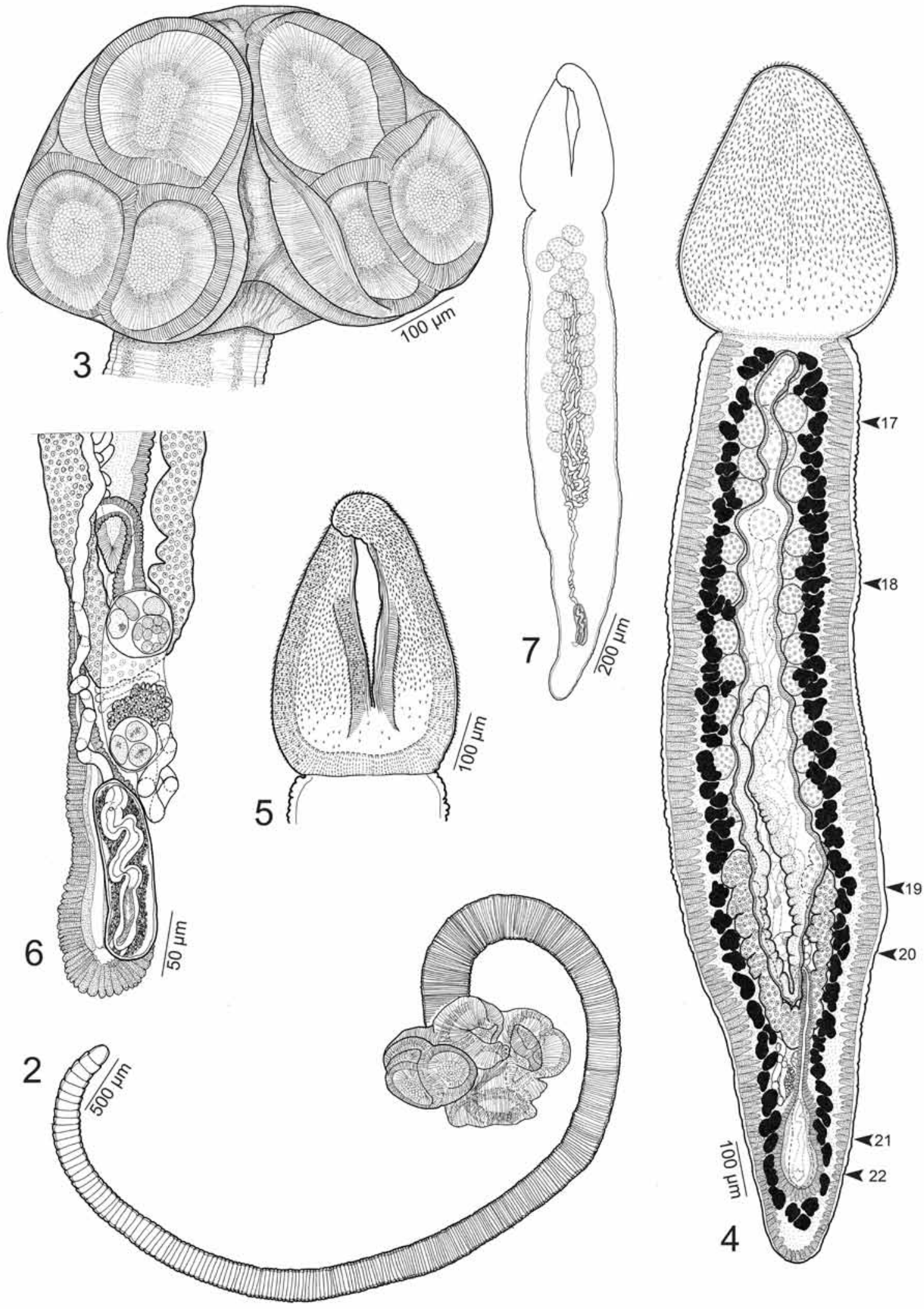

Figs. 2-7. Line drawings of Trilocularia eberti sp. n. Fig. 2. Whole worm. Fig. 3. Scolex. Fig. 4. Dehisced free proglottid, ventral view. Arrowheads indicate location of cross-sections shown in Figs. 17-22. Fig. 5. Anterior attachment region of free proglottid, dorsal view. Fig. 6. Detail of posterior portion of mature proglottid: cirrus sac and vagina, dorsal view. Fig. 7. Sketch of male reproductive system in free proglottid, dorsal view. 

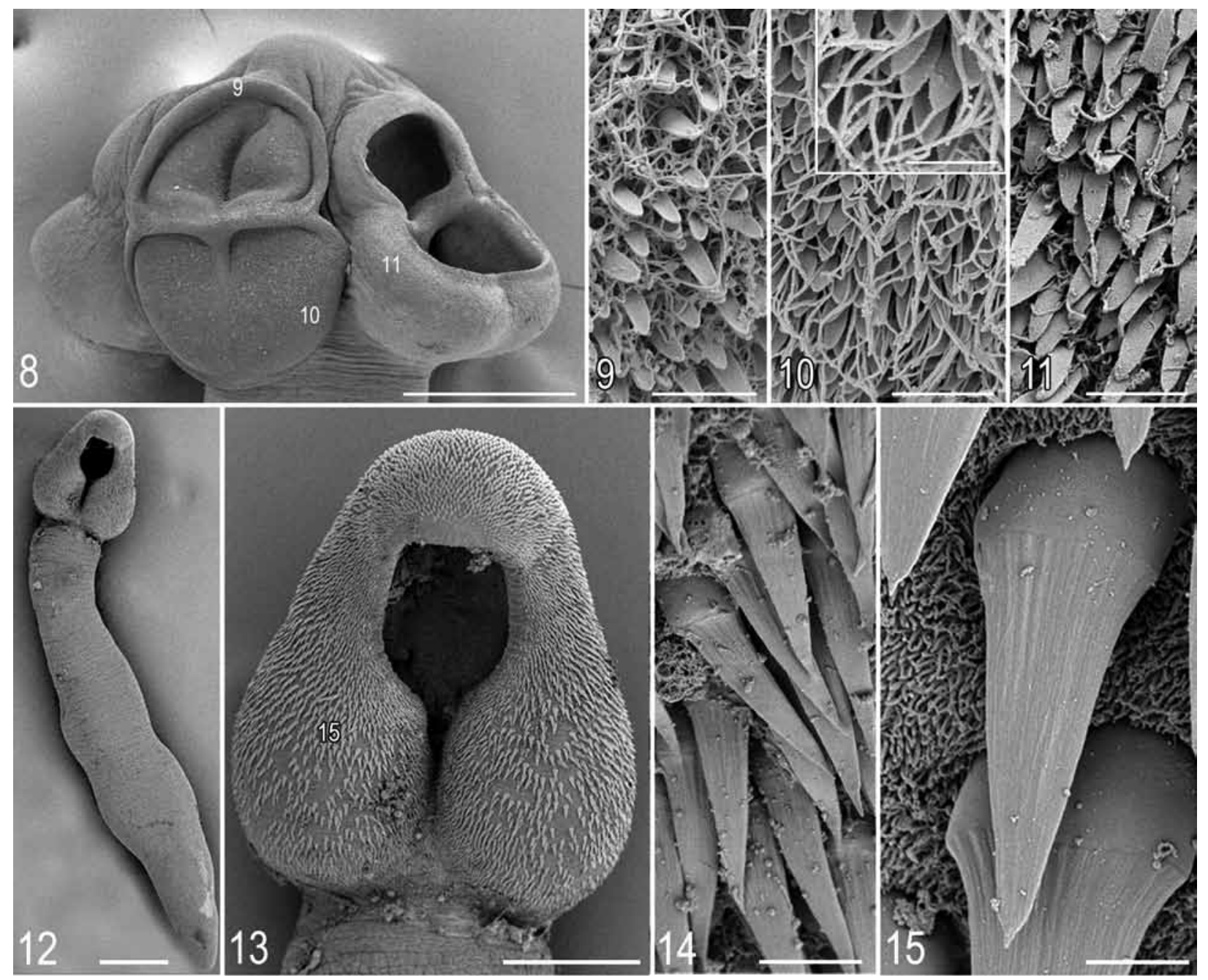

Figs. 8-15. Scanning electron micrographs of Trilocularia eberti sp. n. Note: small numbers in Figs. 8 and 13 correspond to Figs. 9-11 and 15. Fig. 8. Scolex. Fig. 9. Detail of proximal surface of anterior loculus. Fig. 10. Detail of distal surface of medial posterior loculus. Inset: Enlarged view showing long aristate tips on gladiate spinitriches. Fig. 11. Detail of proximal surface of medial posterior loculus. Fig. 12. Mature free proglottid. Fig. 13. Detail of anterior attachment region of mature free proglottid. Fig. 14. Detail of outer surface of anterior attachment region of immature free proglottid. Fig. 15. Detail of outer surface of anterior attachment region of mature free proglottid. Scale bars: Figs. 8, $12=200 \mu \mathrm{m}$; Figs. 9-11, 14, $15=2 \mu \mathrm{m}$; Inset of Fig. $10=1 \mu \mathrm{m}$; Fig. $13=100 \mu \mathrm{m}$.

tids. Worms extremely hyperapolytic (Fig. 2), consisting of up to 200 immature proglottids; $0.48-5.27(2.2 \pm 1.9$; 5) $\mathrm{mm}$ long; greatest width $485-671(549 \pm 72 ; 6)$ at posterior of scolex. Strobila delicate, tapering posteriorly, 154-295 $(226 \pm 56 ; 5)$ wide immediately posterior to scolex, 86-141 (120 \pm 24 ; $)$ wide at posterior end; terminal proglottid extremely immature, 80 long by 86 wide $(\mathrm{n}=1)$. Scolex $286-445(381 \pm 60 ; 6)$ long by $485-671$ $(549 \pm 72 ; 6)$ wide, bearing four oval bothridia; bothridia $278-425(341 \pm 55 ; 5 ; 9)$ long by $210-382(271 \pm 50$; 6 ; 13) wide, each bearing one anterior loculus followed by one pair of posterior loculi (Figs. 3, 8), ratio of width at level of anterior loculus to width of paired loculi 1 : $1.1-1.5(1: 1.3 \pm 0.1 ; 13 ; 6)$; anterior and posterior loculi approximately equal in length; posterior two loculi approximately equal in width; anterior loculus 137-255
$(180 \pm 39 ; 6 ; 10)$ long by $177-281(207 \pm 29 ; 6 ; 15)$ wide; posterior lateral loculus $158-225(185 \pm 27 ; 6 ; 10)$ long by $114-195(138 \pm 25 ; 6 ; 13)$ wide; posterior medial loculus $161-225(183 \pm 25 ; 5 ; 9)$ long by $90-228(134 \pm 35 ; 6$; 14) wide. Cephalic peduncle not seen.

Rim and proximal bothridial surfaces (Figs. 9, 11) with densely arranged aristate gladiate spinitriches interspersed with capilliform filitriches; spinitriches becoming sparser towards more proximal regions of bothridia; distal bothridial surfaces with capilliform filitriches interspersed with aristate gladiate spinitriches with extremely long aristate tips (Fig. 10).

Free proglottids of all ages with conspicuously expanded anterior attachment region; remainder of proglottid housing genital primordia. Lateral margins of ventral surface of anterior attachment region folding ventrally, 
becoming a slit-like aperture with maturity (Fig. 16). Immature free proglottids 667-1094 (889 $\pm 185 ; 4)$ long by 156-220 (195 $\pm 27 ; 4)$ wide. Dorsal and outer recurved surfaces of anterior attachment region of free immature proglottids with acicular filitriches and relatively small gladiate spinitriches; spinitriches 4.4-5.1 (4.8 $\pm 0.3 ; 1 ; 6)$ long by $1.2-1.3(1.3 \pm 0.03 ; 1 ; 4)$ wide at base (Fig. 14).

Free mature, gravid and dehisced proglottids 1.4-2.2 $(1.8 \pm 0.3 ; 14) \mathrm{mm}$ long by $215-381(302 \pm 50 ; 14)$ wide. Anterior attachment region $326-543(419 \pm 54$; 13) long by $302-471(349 \pm 44 ; 13)$ wide, triangular in shape (Figs. 5,13 ) with dorsally recurved margins. Dorsal and outer recurved surfaces of anterior attachment region with capilliform filitriches and large gladiate spinitriches (Fig. 15); spinitriches $8.9-10.6(9.8 \pm 0.5 ; 1 ; 13)$ long by $3.5-4.2$ $(4.0 \pm 0.3 ; 5 ; 1)$ wide at base. Remainder of proglottid uniformly covered with capilliform fillitriches.

Testes $15-37(25 \pm 5 ; 13)$ in number, 34-71 (51 \pm 10 ; $14 ; 42)$ long by $32-71(52 \pm 9 ; 14 ; 42)$ wide, arranged in two irregular columns extending from anterior margin of main body of proglottid to near anterior margin of ovary, one row deep in cross section (Fig. 17). Cirrus sac elongate oval in shape (Fig. 6), 88-186 (132 \pm 23 ; 13) long by $34-48(41 \pm 5 ; 12)$ wide, oriented parallel to long axis of proglottid, located posterior to ovary in posterior-most part of proglottid; cirrus covered with small spinitriches. Vas deferens extensive (Figs. 4, 7), entering anterior extremity of cirrus sac (Fig. 6). Ovary Ushaped in frontal view, bilobed in cross section (Fig. 20), $283-486(372 \pm 65 ; 14)$ long by $99-232(164 \pm 41 ; 14)$ at widest point, anterior to cirrus sac; ovarian lobes 28-63 $(40 \pm 9 ; 21 ; 14)$ wide. Mehlis' gland posterior to ovary. Vagina robust, thick-walled (Figs. 21, 22), straight, ventral to cirrus sac, extending anterior from ootype to level of uterus, then turning posteriorly to open into common, ventral genital atrium (Fig. 6). Common genital pore midventral, near posterior margin of proglottid (Fig. 4). Vitellarium follicular; vitelline follicles in two lateral bands (Fig. 4); each band consisting of one column of follicles (Figs. 19, 20), extending throughout length of main body of proglottid, uninterrupted by ovary; vitelline bands confluent posterior to cirrus sac in posterior extremity of proglottid. Uterus median, ventral, tube-like in immature proglottids, becoming more sacciform in gravid proglottids, extending from ovary to anterior margin of main body of proglottid, with median elongate dehiscence on ventral surface (Fig. 4). Oncospheres 18-26 (22 $\pm 3 ; 8 ; 4)$ long by $17-24(20 \pm 2 ; 8 ; 4)$ wide, packaged in irregular cocoons of $4-8$.

Type and only known host: Squalus cf. mitsukurii (Squaliformes: Squalidae).

Site of infection: Spiral intestine.

Type locality: Indian Ocean, South Africa $\left(36^{\circ} 41.1^{\prime} \mathrm{S}\right.$, $\left.20^{\circ} 37.6^{\prime} \mathrm{E}\right)$; type host captured at depth of $338 \mathrm{~m}$.

Additional localities: None.

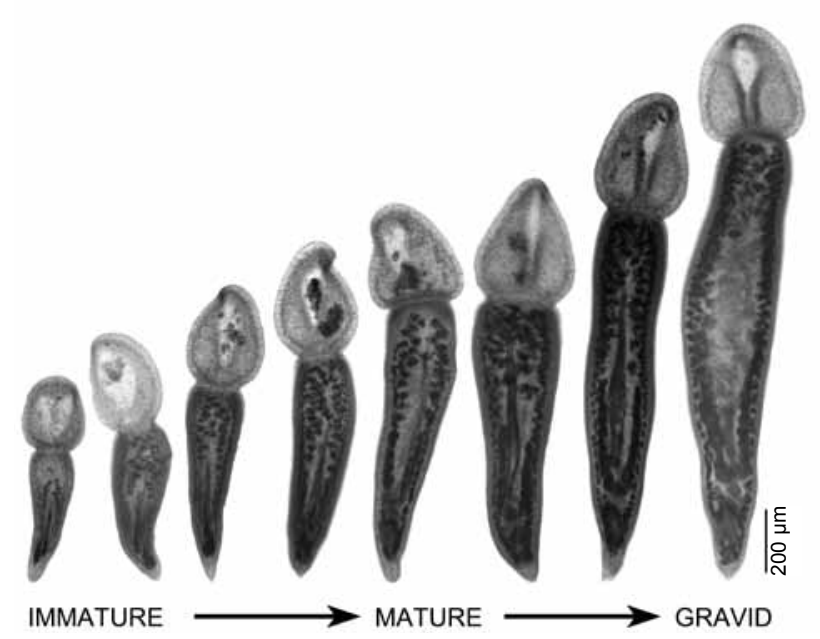

Fig. 16. Light micrographs of free proglottids of Trilocularia eberti sp. n. representing the spectrum of developmental stages found.
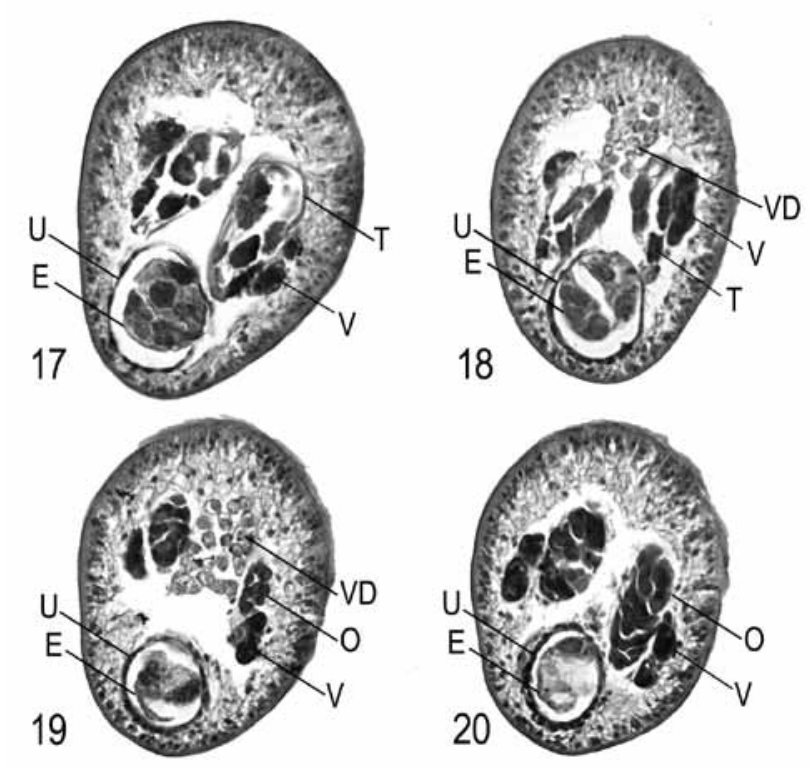

21
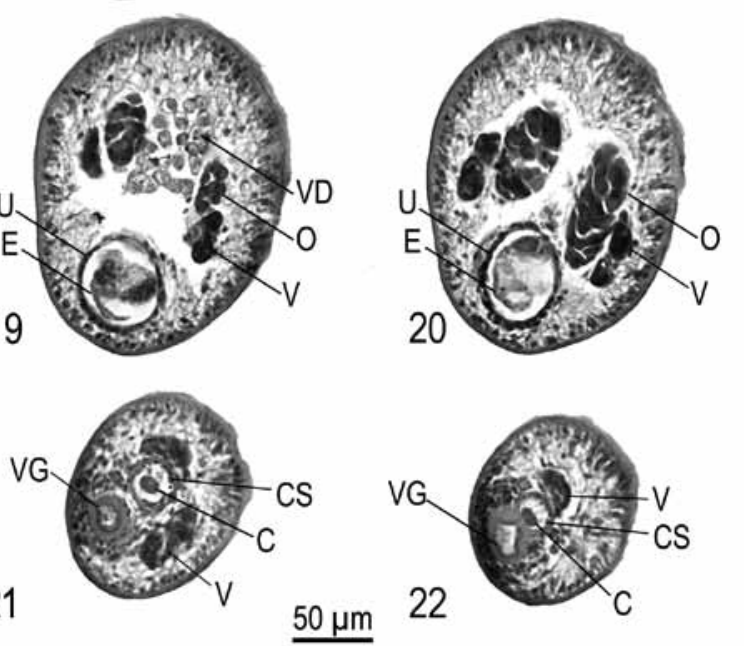

Figs. 17-22. Histological sections of Trilocularia eberti sp. n. Fig. 17. Cross-section through testes. Fig. 18. Cross-section through testes and extensive vas deferens. Fig. 19. Cross-section through ovary arms (bilobed) and extensive vas deferens. Fig. 20. Cross-section through ovary. Fig. 21. Cross-section through cirrus sac and vagina. Fig. 22. Cross-section through cirrus sac and vagina close to genital pore opening. Abbreviations: $\mathrm{C}$ - cirrus; $\mathrm{CS}$ - cirrus sac; $\mathrm{E}$ - eggs; $\mathrm{O}$ - ovary; $\mathrm{T}$ - testes; $\mathrm{U}$ - uterus; V - vitelline follicle; VD - vas deferens; VG - vagina. 


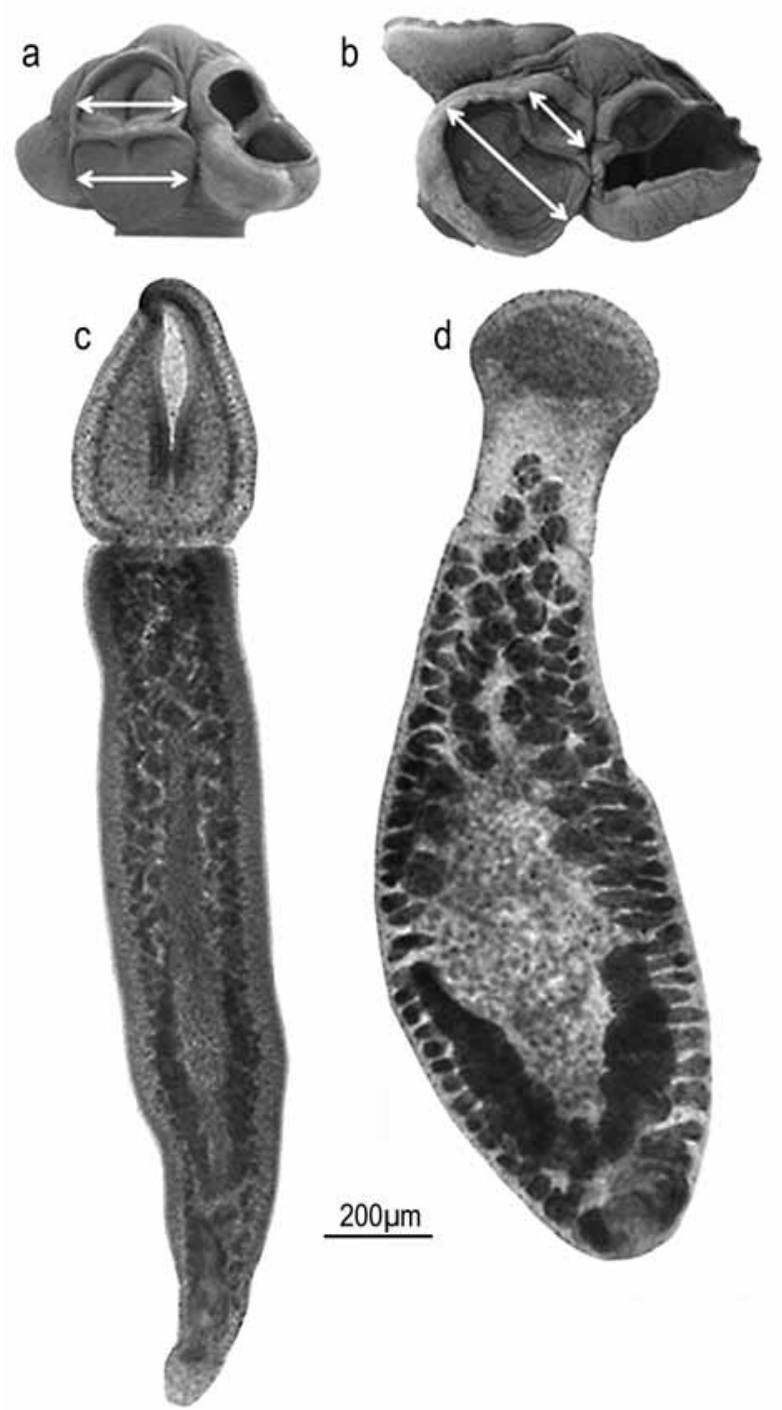

Fig. 23 a-d. Trilocularia eberti sp. n. scolex (a) and free proglottid (c). Trilocularia gracilis scolex (b) and free proglottid (d) for comparison. White arrows on scoleces $(a, b)$ illustrate difference in ratio of anterior loculus to posterior loculi between the two species. a, b - scanning electron micrographs (scoleces); c, d-light micrographs (free proglottids).

Prevale n c e : 2 of 6 sharks sampled (33\%).

Intensity: 2 and 4 worms per host.

Etymology: This species is named in honour of Dr. Dave Ebert, in recognition of his expert assistance with the identification of hosts, and also in anticipation of his formally describing the type host of this species.

Specimens deposited: Holotype - free proglottid (SAMCTA No. 29512); 8 paratypes consisting of whole mounts of one worm, four free proglottids, and cross sections of two gravid free proglottids (SAMCTA Nos. 29513-29519); one paratype free proglottid (IPCAS C-622); 14 paratypes consisting of whole mounts of two worms, eight free proglottids in developmental series (Fig. 16; four immature, three mature, and one gravid), two free proglottids, and cross sections of two gravid free proglottids (LRP Nos. 7869-7885);
Table 1. Total number of worms and free proglottids per host, and estimated proglottid production per worm.

\begin{tabular}{ccccc}
\hline $\begin{array}{c}\text { Host ID } \\
\text { Number }\end{array}$ & $\begin{array}{c}\text { No. of } \\
\text { worms }\end{array}$ & $\begin{array}{c}\text { No. of free } \\
\text { proglottids }\end{array}$ & $\begin{array}{c}\text { Mean No. proglot- } \\
\text { tids per worm }\end{array}$ & $\begin{array}{c}\text { Estimated range } \\
\text { in No. of proglot- } \\
\text { tids per worm }\end{array}$ \\
\hline AF-21 & 2 & 422 & 211 & $1-422$ \\
AF-22 & 4 & 1748 & 437 & $1-1748$ \\
Total & 6 & 2170 & 362 & \\
\hline
\end{tabular}

eight paratypes consisting of whole mounts of one scolex, five free proglottids, and two cross sections of gravid free proglottids (USNPC Nos. 105459-105460). SEM stubs consisting of two scoleces, two immature and five mature free proglottids, retained in second author's personal collection.

Remarks. Trilocularia eberti sp. n. most conspicuously differs from its only congener, Trilocularia gracilis, in the morphology of both its scolex and free proglottids. Whereas in T. eberti sp. n. the width of the anterior loculus is very similar to the combined width of the pair of posterior loculi, in T. gracilis the anterior loculus is much narrower than the pair of posterior loculi $(1: 1.7-2.5$ $[1: 2.0 \pm 0.2 ; 18 ; 9]$ versus $1: 0.7-1.7[1: 1.3 \pm 0.1 ; 13$; 6]) (see Fig. 23a,b). Furthermore, whereas the anterior attachment region of the free proglottids of T. eberti $\mathrm{sp} . \mathrm{n}$. is triangular in shape, with a slit-like opening that is widest at the base and narrows anteriorly, that of $T$. gracilis is rounded with a cup-like opening that narrows at its base (see Fig. 23c,d).

The two infected sharks hosted a total of only two and four worms each. However, both also hosted a substantial number of free proglottids in various stages of development. The number of proglottids found, and their implications for the number of proglottids produced per worm, are provided in Table 1. The largest attached terminal proglottid observed on any of the six worms found measured $80 \mu \mathrm{m}$ in length; the smallest free immature proglottid that was mounted was $667 \mu \mathrm{m}$ long.

\section{DISCUSSION}

One of the major challenges facing free proglottids of extremely hyperapolytic cestode species is maintaining their position in their host's intestine for the period of time required for them to mature, mate and ultimately produce eggs (Caira and Reyda 2005). In order to maintain their position without the aid of a scolex, hyperapolytic free proglottids have been found to exhibit modified anterior regions that bear unusually enlarged spinitriches, presumably to aid in attachment to the intestinal mucosa of their hosts (Euzet 1952, McCullough and Fairweather 1983, Caira et al. 2007, Fyler 2011). The free proglottids of Trilocularia eberti conform with this observation. The smallest immature free proglottid of $T$. eberti observed (667 $\mu \mathrm{m}$ long) was still about 2.5 times smaller than the smallest mature free proglottids seen, and it is evident from examination of a developmental series of free pro- 
glottids (from immature to gravid - Fig. 16) that the anterior attachment region is well developed early on, constituting greater than one-third of the proglottid length $(1: 2.8)$ in immature proglottids, but approximately one-fourth or less of proglottid length in gravid proglottids $(1: 4.2)$. However, comparison of the size of the spinitriches on the anterior attachment region of immature free proglottids to that of the spinitriches on the anterior attachment region of mature free proglottids (Fig. 14 vs. Fig. 15) reveals that, while gladiate spinitriches are present in both developmental stages, they differ in size; those of mature free proglottids are twice as long and three times as wide as those observed on immature free proglottids. Furthermore, it appears that once the anterior attachment region is of sufficient size (= approx. $420 \mu \mathrm{m}$ long), growth of the attachment structure stops and is concentrated in the posterior part of the proglottid.

Given the complex, multiple-host life cycles of marine cestodes, in combination with the vast nature of the marine environment into which their eggs are released, it is assumed that the cestodes of marine vertebrates must be incredibly fecund in order to inundate their surrounding environment with a sufficiently large number eggs so that the resulting larvae are more likely to ultimately encounter future hosts (Caira and Reyda 2005). The existence of tiny hyperapolytic taxa in this context is, at least initially, particularly puzzling. Due to the hyperapolytic nature of T. eberti, it is difficult to determine exactly how many free proglottids a single strobila is capable of producing. However, the low intensity of the infection seen here allows for a reasonable estimate of the number of proglottids produced per worm to be calculated; the results are somewhat surprising. Based on the number of worms and the number of free proglottids found, we estimate that a single individual of T. eberti produces, on average, 362 proglottids per worm, although potentially, up to as many as 1748 free proglottids (see Table 1). This suggests that the small size of an extremely hyperapolytic worm, such as T. eberti (the largest worm of which was only $5.3 \mathrm{~mm}$ in length), can be misleading in terms of the biomass actually produced over the course of its life, and in turn, thus also its overall fecundity. For example, if the average number of free proglottids produced by each strobila of $T$. eberti (i.e., 362) is multiplied by the average size of a gravid free proglottid (i.e., $1.8 \mathrm{~mm}$ ), the total length a single worm could achieve if it did not drop its proglottids (i.e., if it were anapolytic) is an astounding $65.2 \mathrm{~cm}$ ! Of course it is probable that some scoleces and/or free proglottids had been expelled from the host intestine prior to examination, and it is also possible that immature free proglottids (particularly those between the size of the terminal proglottid on the strobila and the smallest immature free proglottid recovered) were present and not found. Nonetheless, these estimates provide a sense of average fecundity at one moment in time. It has been hypothesized by McCullough and Fairweather (1983) that the hyperapolytic nature of T. gracilis (as T. acanthiaevulgaris) allows for an increase in the number of proglottids without the strobila becoming cumbersomely long, which seems to be supported by the findings in its congener, T. eberti.

The genus Trilocularia now houses two species, each parasitizing a different species of Squalus. A total of 27 species of Squalus (see Froese and Pauly 2012, Naylor et al. 2012), 13 of which have been described since 2007 (Last et al. 2007, Ebert et al. 2010, White and Iglésias 2011), are now known. Only a subset (seven species) of these have been examined for cestodes, but the majority of these studies have focused on the order Trypanorhyncha (e.g., Palm 2004, Olson et al. 2010). Only four species of Squalus (S. megalops [Macleay], S. melanurus Fourmanoir et Rivaton, S. suckleyi [Girard], and S. acanthias) have been reported to host tetraphyllideans (see Olsson 1869, Yamaguti 1952, Robinson 1965, Williams 1968, Vasileva et al. 2002, Beveridge and Justine 2006), and of these only $S$. acanthias has been reported to host Trilocular$i a$. It is unknown if additional tetraphyllideans were not seen in the other hosts, or if they were encountered and simply not reported and/or described. We note that our preliminary investigations of limited material from the spiral intestines of two other Squalus species (S. suckleyi and $S$. cubensis) have yielded material of what appear to be new species of Trilocularia. This suggests additional diversity of Trilocularia is likely to exist in species of $S q$ ualus not yet sampled.

Acknowledgments. We thank Tracey Fairweather and Rob Leslie of the Department of Agriculture, Forestry and Fisheries, Cape Town, South Africa, for making JNC's participation in the April 2010 cruise of the FRV Africana possible, the crew and scientific staff of the FRV Africana for helping collect the sharks, and Kirsten Jensen for assisting with the collection of the cestodes. This research was supported in part by NSF PBI award Nos. 0818823 and 0818696.

\section{REFERENCES}

Alexander C.G. 1963: Tetraphyllidean and diphyllidean cestodes of New Zealand selachians. Trans. Roy. Soc. N. Zealand, Zoology 3: $117-142$.

Beveridge I., Justine J.-L. 2006: Gilquiniid cestodes (Trypanorhyncha) from elasmobranch fishes off New Caledonia with descriptions of two new genera and a new species. Syst. Parasitol. 65: $235-249$. de Chambrier A., Zehnder M., Vaucher C., Mariaux J. 2004: The evolution of the Proteocephalidea (Platyhelminthes: Eucestoda) based on an enlarged molecular phylogeny, with comments on their uterine development. Syst. Parasitol. 57: $159-171$.

Caira J.N., Jensen K., Rajan C. 2007: Seven new Yorkeria species (Cestoda: Tetraphyllidea) from Borneo and Australia and 
their implications for identification of Chiloscyllium (Elasmobranchii: Orectolobiformes) species. J. Parasitol. 93: 357-376.

Caira J.N., Reyda F.B. 2005: Marine eucestodes. In K. Rohde (Ed.), Marine Parasitology. CISRO Publishing, Collingwood. pp. 92-105.

Chervy L. 2009: Unified terminology for cestodes microtriches: a proposal from the participants of the International Workshops on Cestode Systematics in 2002-2008. Folia Parasitol. 56: $199-230$

Ebert D.A., White W.T., Goldman K.J., Compagno L.J.V., DaLY-ENGEL T.S., WARD R.D. 2010: Reevaluation and redescription of Squalus suckleyi (Girard, 1854) from the North Pacific, with comments on the Squalus acanthias subgroup (Squaliformes: Squalidae: Squalus). Zootaxa 2612: 22-40.

EuZET L. 1952: Sur Trilocularia acanthiae-vulgaris (Olsson 1866) Olsson 1867 Cestoda Tetraphyllidea. Bull. Inst. Oceanogr. No. 1010: $1-6$.

Henderson A.C., Flannery K., Dunne J. 2002: An investigation into the metazoan parasites of the spiny dogfish (Squalus acanthias L.), off the west coast of Ireland. J. Nat. Hist. 36: 1747-1760.

Froese R., Pauly D. (Eds.) 2012: FishBase. World Wide Web electronic publication, www.fishbase.org, version 02/2012.

Fyler C.A. 2011: An extremely hyperapolytic Acanthobothrium species (Cestoda: Tetraphyllidea) from the Japanese wobbegong, Orectolobus japonicus (Elasmobranchii: Orectolobiformes) in Taiwan. Comp. Parasitol. 78: 4-14.

Last P.R., White W.T., Pogonoski J.J. (Eds.) 2007: Descriptions of New Dogfishes of the genus Squalus (Squaloidea: Squalidae). CSIRO Marine and Atmospheric Research Paper No. 014. Hobart, $121 \mathrm{pp}$.

McCullough J.S., Fairweather I. 1983: A SEM study of the cestodes Trilocularia acanthiaevulgaris, Phyllobothrium squali and Gilquinia squali from the spiny dogfish. Parasitol. Res. 69: 655-665.

McCullough J.S., Fairweather I. 1984: A comparative study of Trilocularia acanthiaevulgaris Olsson 1867 (Cestoda, Tetra-

Received 12 January 2012 phyllidea) from the stomach and spiral valve of the spiny dogfish. Z. Parasitenkd. 70: 797-807.

McCullough J.S., Fairweather I., Montgomery W.I. 1986: The seasonal occurrence of Trilocularia acanthiaevulgaris (Cestoda: Tetraphyllidea) from spiny dogfish in the Irish Sea. Parasitology 93: 153-162.

Naylor G.J.P., Caira J.N., Jensen K., Rosana K.A.M., White W.T., LAST P.R. 2012: A DNA sequence based approach to the identification of shark and ray species and its implications for global elasmobranch diversity and parasitology. Bull. Am. Mus. Nat. Hist. 754: 1-261.

Olson P.D., Caira J.N., Jensen K., Overstreet R.M., Palm H.W., Beveridge I. 2010: Evolution of the trypanorhynch tapeworms: parasite phylogeny supports independent lineages of sharks and rays. Int. J. Parasitol. 40: 223-242.

Olsson P. 1866-1867: [Entozoa, observed in Scandinavian marine fish. I. Platyhelminthes.] Lunds Univer., Math. Nat. 3 (3): 1-59. (In Swedish.)

OLSSON P. 1869: [New parasitic genera of copepods and platyhelminths.] Lunds Univer., Math. Nat. 7: 1-6. (In Swedish.)

PaLm H.W. 2004: The Trypanorhyncha Diesing, 1863. PKSPL-IPB Press, Bogor, 710 pp.

Robinson E.S. 1965: Cestoda (Tetraphyllidea and Trypanorhyncha) from marine fishes of New South Wales. Rec. Aust. Mus. 26 (15): 341-348.

Vasileva G.P., Dimitrov G.I., Georgiev B.B. 2002: Phyllobothrium squali Yamaguti, 1952 (Tetraphyllidea, Phyllobothriidae): redescription and first record in the Black Sea. Syst. Parasitol. 53: 49-59.

White W.T., IgLÉsias S.P. 2011: Squalus formosus, a new species of spurdog shark (Squaliformes: Squalidae), from the western North Pacific Ocean. J. Fish Biol. 79: 954-968.

Williams H.H. 1968: Taxonomy, ecology and host-specificity of some Phyllobothriidae (Cestoda: Tetraphyllidea), a critical revision of Phyllobothrium Beneden, 1849 and comments on some allied genera. Phil. Trans. R. Soc. Lond. B. 253: 231-307.

Yamaguti S. 1952: Studies on the helminth fauna of Japan. Part 49. Cestodes of fishes, II. Acta Med. Okayama 8: 1-76.

Accepted 5 April 2012 